\title{
FEAPS, 50 AÑOS DE UNIÓN POR LAS PERSONAS CON DISCAPACIDAD INTELECTUAL Y POR SUS FAMILIAS
}

\section{FEAPS, 50 years of union for people with intellectual disabilities and their families}

Juan José Lacasta Reoyo

Confederación Española de Organizaciones en Favor de las Personas con Discapacidad Intelectual (FEAPS)

juanjolacasta@feaps.org

Recepción: 3 de diciembre de 2014

Fecha de aceptación definitiva: 16 de diciembre de 2014

Biblid. [0210-1696 (2015) vol. 46 (1), n. ${ }^{\circ} 253$, enero-marzo; 41-65]

Resumen: La Confederación Española de Organizaciones en Favor de las Personas con Discapacidad Intelectual o del Desarrollo ha cumplido 50 años. Se analizan en el artículo los cambios paradigmáticos que se han sucedido en estos años. En definitiva, cómo ha cambiado la percepción social y los modelos mentales en relación a las personas con discapacidad intelectual, la terminología, el ejercicio de la ciudadanía, los modelos de intervención, la evolución de los servicios, el rol de las familias, el entorno político y social y, paralelamente, cómo han evolucionado FEAPS y su proyecto y qué papel y capacidad de incidencia ha tenido en los logros y progresos alcanzados desde 1964.

Palabras Clave: historia de la discapacidad intelectual; movimiento asociativo; percepción social; ciudadanía; incidencia política y social; FEAPS.

AвSTRAct: The Spanish Confederation of Organizations for Persons with Intellectual Disability and Development has completed 50 years. Paradigmatic changes that have happened in these years are analyzed in the article. In short, how it has changed the social perception and mental models in relation to people with intellectual disabilities, 
terminology, the exercise of citizenship, intervention models, the evolution of services, the role of families, the environment political and social and, in parallel, how it has evolved FEAPS and your project and what role and power of influence has had on the achievements and progress made since 1964.

KEY WORDS: History of intellectual disability; associations; social perception; citizenship; political and social impact; FEAPS.

\section{5}

a Federación Española de Asociaciones Pro Subnormales (FEAPS) nació el 24 de abril de 1964. Nació hace 50 años, por tanto, lo que es hoy la Confederación Española de Organizaciones en favor de las Personas con Discapacidad Intelectual o del Desarrollo (FEAPS). Si comparamos las denominaciones, con una ligera observación, se aprecian ya cambios evolutivos importantes. De federación a confederación; de asociaciones a organizaciones; de subnormales a personas con discapacidad intelectual o del desarrollo. No es más que el nombre, pero ya sólo éste apunta que entre 1964 a 2014 ha habido desarrollos tanto en la filosofía del afrontamiento a la discapacidad y del acercamiento a las personas con discapacidad, como en la configuración organizacional del Movimiento Asociativo que FEAPS ha reunido durante este último medio siglo.

De eso trata este artículo, de la evolución, durante estos 50 años, de las maneras de abordar los retos que ha venido proponiendo el colectivo de personas con discapacidad intelectual y sus familias -interpretados a lo largo de este periodo de manera muy distinta-, de los instrumentos de los que el Movimiento Asociativo FEAPS se ha ido dotando para desafiarlos y del papel más o menos protagonista que FEAPS ha ejercido en los avances de este sector social, siempre en una medida mayor o menor, excluido y segregado. Trata también de la descripción de los cambios paradigmáticos científicos que han ido conformando las estrategias de afrontamiento, las percepciones y las políticas sociales.

FEAPS, confederación, concita la integración de un movimiento asociativo que está extendido por toda España. Un movimiento asociativo, una red, integrado por 884 entidades agrupadas en 17 federaciones de ámbito autonómico - 1 federación por cada comunidad autónoma-. La confederación, como entidad jurídica distinta de las federaciones y entidades que la componen, es la que cumple los 50 años; hay entidades miembros que son más añejas que la propia confederación, por ello, cuando, en adelante, hablemos de FEAPS nos estaremos refiriendo al conjunto del movimiento asociativo que representa: las entidades, las federaciones y la propia confederación. Así que cuando hablemos del papel de FEAPS en determinadas situaciones o logros, salvo que se advierta expresamente, estaremos refiriéndonos al papel del movimiento asociativo que FEAPS representa.

Los cambios en la denominación de la confederación serán, en consecuencia, nuestra guía: las personas, las entidades, la configuración organizativa y el entorno como el espacio vital en el que se desenvuelven, mejor o peor, las personas y las organizaciones. 


\section{Lo que verdaderamente importa: las personas y sus familias}

\section{La percepción social de las personas con discapacidad intelectual o del desarrollo}

En estos 50 años ha habido grandes cambios en la percepción social de las personas, percepción que se ha manifestado tanto en el uso de una determinada nomenclatura como en actitudes y comportamientos más o menos discriminatorios o excluyentes y a veces degradantes, hasta situaciones más inclusivas.

Hoy concebimos en el mundo técnico, científico y del pensamiento social que las personas con discapacidad intelectual o del desarrollo son ciudadanos de pleno derecho y que su vida está (debe estar) en la comunidad. Desde una perspectiva ética hablamos de personas completas con toda su dignidad. En el Código Ético de FEAPS se recoge en el principio de Dignidad y Valor de la Persona:

La persona con discapacidad intelectual, como individuo, como persona, en cuanto tal ser humano, tiene valor en sí y por sí misma. Con sus limitaciones y capacidades es un ser humano con su dignidad, en esencia como cualquier otro. Es, en consecuencia, un individuo con sus características, intereses y fines propios e irrepetibles, con dignidad y valor propio, equiparables a los de cualquier otra persona.

Sin embargo, ese pensamiento que se ha establecido en el discurso y en los documentos de las personas y de las organizaciones que conviven con las personas con discapacidad intelectual y las apoyan no siempre tiene una correlación directa con sus creencias y supuestos básicos y, en consecuencia, con sus actitudes y comportamientos; así que vivimos en una época en la que la segregación y la discriminación aún permanecen, pero soterradas en un discurso muy correcto que, a base de usarlo, puede darnos la impresión de que hemos hecho desaparecer las actitudes sobreprotectoras y paternalistas, siempre excluyentes. Aun así, el uso de un lenguaje correcto orientado a la dignidad de las personas también ayuda a cambiar pensamientos y los pensamientos a modificar los sentimientos y las actitudes.

Es éste un momento interesante, no sólo por el discurso cada vez más ahormado, sino porque se están poniendo en práctica acciones, puntuales y permanentes, que están demostrando que el discurso tiene muchas posibilidades de ser llevado a la práctica. Al final, la demostración práctica será la que tendrá más impacto en el cambio de creencias.

\section{La evolución terminológica}

A lo largo de las décadas de los últimos 50 años ha habido cambios significativos en el imaginario colectivo de las personas con discapacidad intelectual. Y ese imaginario ha tenido consecuencias en las estrategias de servicios y en las políticas públicas. Precisamente, la evolución de la terminología para dirigirse a las personas con discapacidad intelectual o del desarrollo ha ido funcionando como un síntoma 
que ha expresado a lo largo del tiempo los cambios de percepción y de valoración de este colectivo. Todas las expresiones que nacieron con una intención descriptiva y clasificatoria desde la ciencia y sin ánimo peyorativo acabaron siendo usadas como arma arrojadiza e insulto: idiota, imbécil, subnormal, anormal, deficiente, mongólico, retrasado, profundo...

Para repasar algunos ejemplos de la evolución terminológica, en 1963, en Beirut se celebró el Congreso mundial de los derechos del niño inadaptado, y llamaban niño inadaptado al niño con discapacidad intelectual. También en 1963, se celebraron las primeras Jornadas de Estudio sobre el Problema de los Niños Subnormales. En 1968 FEAPS celebró el primer día nacional del subnormal. La propia "s" de FEAPS proviene de la palabra subnormal. En 1971 se crea el SEREM, Servicio de Rehabilitación y Recuperación del Minusválido, un organismo público. En 1974 en la celebración del Minusval 74, FEAPS pide que se sustituya la palabra “subnormal” por resultar muy peyorativa. En 1978 se proclama la Constitución española y en su artículo 43 habla de los derechos de los disminuidos psíquicos. En 1981 se celebra el Año internacional del Minusválido. En 1982 se promulga la LISMI, la Ley de Integración Social del Minusválido; y se entiende por minusválido en la propia LISMI a toda persona cuyas posibilidades de integración educativa, laboral o social se encuentren reducidas como consecuencia de una deficiencia, previsiblemente permanente, en sus capacidades físicas, psíquicas o sensoriales. En 1984, FEAPS organiza, junto con la Liga Internacional de Asociaciones (ILSMH), la Conferencia internacional sobre deficiencia mental profunda. En 1986 el término subnormal se sustituye oficialmente por el de minusválido. En 1991 se celebra la Feria Nacional de Trabajadores con Discapacidad, DISCAP. En 1992 se celebró la Primera Conferencia Nacional, organizada por el INSERSO, sobre la Sexualidad de las Personas con Minusvalía Psíquica y la Asamblea de la ONU aprobó una resolución que declaraba cada 3 de diciembre como el Día Internacional de las Personas con Discapacidad. En 1996 FEAPS celebra su primer Congreso en Toledo con el lema: "Porque las personas con deficiencia mental necesitan que nuestra organización mejore”. En 2002 se publica la Definición de Retraso Mental de la Asociación Americana para el Retraso Mental (AAMR). En 1997 FEAPS reforma sus estatutos e incorpora el término personas con retraso mental. En la Asamblea General de FEAPS de 2001, dos representantes de los grupos de autogestores hicieron una demanda: “Queremos que se sustituyan las palabras 'retraso mental' por 'discapacidad intelectual' en todos los papeles, sobres, sellos, tampones, etc.”. En la Asamblea de 2002, se acuerda cambiar en los estatutos la denominación de FEAPS, pasó a llamarse "Confederación Española de Organizaciones en favor de las Personas con Discapacidad Intelectual”. Posteriormente la Asociación Americana pasó a denominarse Asociación Americana de Discapacidades Intelectuales y del Desarrollo (AAIDD).

También hemos asistido en este tiempo a la utilización bienintencionada de eufemismos o expresiones sublimadas a la hora de denominar a las personas con discapacidad intelectual: “niños distintos”, “ángeles”, “inocentes”...

Las asociaciones del movimiento asociativo han ido incorporando en sus siglas la evolución terminológica relatada. Algunas han y siguen siendo creativas y han utilizado términos como niños diferentes o niños con necesidades diversas, personas con capacidades

(C) Ediciones Universidad de Salamanca

Siglo Cero, vol. 46 (1), n. ${ }^{\circ} 253,2015$, enero-marzo, pp. 41-65 
diferentes o simplemente la denominación del síndrome o tipo de discapacidad: niños con Sindrome de Down, personas con Trastorno del Espectro Autista (TEA)...

Lo cierto es que han convivido durante varias décadas distintas nomenclaturas, todas ellas con sus diferentes connotaciones. La Clasificación Internacional de Deficiencias, Discapacidades y Minusvalías (CIDDM) de la OMS en 1980 viene a aclarar términos y establece que la deficiencia es "toda pérdida o anomalía de una estructura, o función psicológica, fisiológica o anatómica”; la discapacidad es "toda restricción o ausencia (debido a una deficiencia) de la capacidad de realizar una actividad de la forma, o dentro del margen, que se considera normal para un ser humano"; y la minusvalía "es una situación de desventaja para un individuo determinado, de una deficiencia o de una discapacidad, que limita o impide el desarrollo de un rol que es normal en su caso, en función de la edad, sexo y factores culturales y sociales".

Otro elemento que ha venido cumpliendo un papel de dignificación en la terminología ha sido anteponer, a la condición de discapacidad, la palabra persona. O, mejor dicho, anteponer la persona a cualquier tipo de información que se pueda dar sobre ella. Al principio era, por ejemplo, persona deficiente mental y después esta expresión se matizó con la preposición "con”, persona con deficiencia mental, actualmente, persona con discapacidad intelectual. Esta fórmula poniendo la persona delante de la condición de discapacidad se ha incorporado al estilo y al lenguaje entendido como correcto en la mayoría de las organizaciones y estamentos públicos, aunque no siempre los medios de comunicación tienen un lenguaje correcto en este sentido. Ha sido la medida más efectiva, en lo que a la terminología se refiere para, a partir de ahí, poder configurar un estado de visión colectiva que ayude a una percepción social ajustada a una visión digna de las personas con discapacidad intelectual.

Más allá de la nomenclatura, aunque va muy ligado a ella, hay que contemplar la evolución de la valoración y, a consecuencia de ella, de la percepción social de las personas con discapacidad intelectual. A lo largo de este medio siglo, podemos apreciar que ha habido avances significativos positivos tanto en la percepción de los más allegados como de las personas y colectivos sociales que no han tenido una relación directa con las personas.

Así podemos decir que en las familias, gracias, en gran parte, a la intervención cercana e intensa de las asociaciones, se ha ido pasando de un sentimiento de tragedia, de culpa o de vergüenza, casi inabordables, a conocer y asumir un problema, afrontable, y a la convicción de que tener un hijo o hija con discapacidad no es, ni mucho menos, sinónimo de infelicidad.

\section{De la invisibilidad a la visibilidad}

También podemos decir que, en este periodo de tiempo, venimos de la invisibilidad absoluta de las personas a una cada vez mayor visibilidad. Elena Saiz, madre de Elena, con síndrome de Down, dice que en 1963 llegó por primera vez a una asociación de personas con discapacidad y que 
cuando pienso en los cambios más importantes que se han producido en todo este tiempo, en relación con nuestro mundo y nuestro sector y, concretamente, en las personas con discapacidad, llego a la conclusión de que ahora son visibles (...) Estos niños y niñas eran, en casi todos los sentidos, invisibles. Con el tiempo me di cuenta que algunos los consideraban apestados. Cuando supe que mi hija era como era, inmediatamente pensé que bajo ningún concepto la iba a esconder... ${ }^{1}$.

FEAPS y sus organizaciones y entidades han hecho un esfuerzo enorme de visibilización de las personas. Al principio con campañas y semanas de información, posteriormente y de manera más eficaz con actividades en la comunidad donde la presencia social era el objetivo principal. Esa presencia social ha ido evolucionando y cada vez es de mayor calidad. Al inicio, tal objetivo no estaba contemplado: los grupos de personas, por ejemplo en colonias de verano, iban a lugares apartados. Había intercambios de residentes entre residencias de entidades distintas para veranear. Con el tiempo grupos numerosos invadían pueblos o locales de ocio. En la actualidad hay una enorme variedad de actividades que no parten sólo de las entidades, sino de la iniciativa de las propias personas. La presencia en la escuela, en el trabajo, en el ocio, en la participación social en la comunidad, en el voluntariado... están propiciando mayor y mayor visibilidad y, en consecuencia, mayor conocimiento social y una reducción de los estereotipos.

Es cierto, las personas con discapacidad intelectual son más visibles, pero ¿qué ve la sociedad?, ¿qué imagen se le ofrece?

Ya en 1984, en un encuentro en Madrid de los primeros “autogestores” del grupo La Propia Voz de la Asociación Bona Gent de Valencia, éstos manifestaron:

Observamos como mucha de la gente que se acerca a nosotros lo hace con reparos, con lástima, como para no herirnos. Sentimos un rechazo que nos cohíbe y nos impide desarrollar todas nuestras posibilidades. Sentimos un exceso de proteccionismo y que se toman conclusiones y medidas que nos afectan directamente sin contar con nosotros para nada.

En 1991, el VI Seminario Iberoaméricano sobre Discapacidad e Información se manifestó en contra la imagen estereotipada. Alguna de sus conclusiones fueron: Es usual la imagen peyorativa de los discapacitados en la publicidad; la persona con discapacidad no tiene que ser noticia si no existen razones para ser noticia; es precisa la normalización de la información sobre el sector; hay posibilidades de participar e incidir en los medios de comunicación social. Hay que buscar los caminos para hacerlo 2 .

No cabe duda de que las estrategias de visibilización del colectivo de las personas con discapacidad intelectual ha sido un motivo constante de debate en el movimiento asociativo. Es necesario apuntar algunos criterios que se han ido conformando a lo largo de estos años: no utilizar la imagen para movilizar sentimientos de pena; no utilizar

1 Carta de Elena Saiz, madre de Elena Gómez. Las asociaciones son estupendas. Te arropan y hacen que no te sientas sola.

2 VI Seminario Iberoaméricano sobre Discapacidad e Información, organizado por el Real Patronato de Prevención y Atención a Personas con Minusvalía, con el apoyo de FEAPS. 
sólo imágenes infantiles; no utilizar sólo imágenes de personas con síndrome de Down; utilizar imágenes de personas más en la comunidad que en centros o servicios; utilizar más las situaciones de alegría...

Lo cierto es que estos criterios que se han ido acordando de manera no explícita han ido conformando una proyección de imagen de las personas en la actualidad, otra vez estereotipada, que quizás habría que revisar. La imagen social que generalmente se proyecta, tanto por nuestras entidades, como por empresas que anuncian su responsabilidad social, es una imagen "happy", de constante felicidad y alegría, con un entorno almibarado protector -en una empresa o en el ocio-, con compañeros y ciudadanos felices... Es una imagen no siempre real que esconde situaciones de verdadera exclusión y discriminación y que puede dar a entender que no es necesaria una lucha por la conquista de sus derechos sociales.

De la infancia a la edad adulta

Otro cambio significativo en la percepción social y asociativa ha sido el de ir abandonando cada vez con más fuerza la infantilización de las personas con discapacidad intelectual por adultas que éstas fueran. En la primera década todos y todas eran niños; en la segunda y tercera, alcanzaron el estatus de chicos -aún se sigue utilizando-; en la cuarta se empezó a hablar de adultos y de hombres y mujeres; en la quinta hablamos también de hombres y mujeres y de ciudadanos.

Lo cierto es que el uso del lenguaje infantilizador, además de sobreprotector, es profundamente discriminador. Quien cree en el fondo de su ser que una persona con discapacidad intelectual no es una persona entera, completa, con toda su dignidad, creerá que esa persona está siempre sin terminar, sin hacer y sin posibilidades de ser completa. De ahí los eternos "niños" o eternos "chicos". A quienes consideremos niños o chicos no les podremos ofrecer nunca la oportunidad de afrontar y decidir sobre su propia vida, ni afrontar en serio su participación en la vida y en la comunidad en la que viven. No podremos ni sabremos empoderar a quienes no creemos que puedan empoderarse.

Estamos en el camino. Usamos un lenguaje mucho más adecuado y ese lenguaje, como expresaba antes, ayuda a cambiar actitudes. No obstante, aunque usemos ahora un lenguaje más adecuado a sus derechos, ¿cuándo consideraremos realmente que las personas con discapacidad intelectual han superado la adolescencia? Éste sea quizás el principal reto al que debemos enfrentarnos en los próximos años.

De inútiles a la aportación de valor social

Ha habido otro cambio importante en la percepción social. Vamos pasando, poco a poco, de la percepción completa de seres “inútiles” que no pueden aportar nada, que son meros perceptores sociales de prestaciones y servicios y que suponen un gasto social enorme, a hombres y mujeres, ciudadanos y ciudadanas "útiles" que aportan 
valor, ya sea como trabajadores, como compañeros, como voluntarios o como participantes en las actividades de la comunidad. Se va pasando de la creencia de que "no pueden", a que "puede que puedan”, a "sí pueden” y, lo que es más importante todavía, a "sí puedo". El esfuerzo de FEAPS en la creación de empleo con fórmulas más o menos protegidas, en la promoción del arte y la artesanía, en la educación, en el deporte, van ofreciendo, a lo largo del tiempo, una imagen cada vez más activa de las personas. Por ejemplo, en la campaña de Integración Laboral que llevó a cabo FEAPS con la colaboración de las otras plataformas de la discapacidad, debajo de una fotografía en la que aparecían dos personas, las dos con guardapolvo, una con discapacidad intelectual y otra sin ella, con un producto idéntico en la mano cada una, aparecía el lema: "Sería capaz de encontrar alguna diferencia”. El movimiento asociativo ha realizado grandes esfuerzos en estos años por presentar una imagen activa y útil de las personas con discapacidad intelectual.

Además hay una utilidad que va más allá. Si el movimiento asociativo como principal movilizador de los derechos de este colectivo y las propias personas con discapacidad intelectual son capaces de hacer visible el valor de dignidad de las personas para cambiar los modelos mentales de la sociedad, se podrá conseguir una sociedad mucho más inclusiva, con mayor capital social y con menos posibilidades de discriminar y excluir a cualquier persona o colectivo por cualquier condición que lleven aparejada. La valorización de las personas con discapacidad intelectual puede suponer la mayor fuente de transformación social de la que podemos disponer. El cambio en las personas, el cambio en la percepción de las personas y el cambio social, con el papel catalizador del movimiento asociativo, son cambios que se realimentarán recíprocamente si se trabajan con cierta inteligencia estratégica.

Del impulso social a la segregación a la participación social

Otro cambio importante en la percepción del colectivo ha sido pasar de una idea claramente asentada y sin fisuras de considerar que las personas con discapacidad intelectual debían ser atendidas en instituciones segregadas a, erosionando paulatinamente esta idea, abominar de la separación y ver con cada vez más aceptación la inclusión y la participación social.

En la entrevista que ofrece Ernesto Puerto, primer presidente de FEAPS, en el vigésimo aniversario de FEAPS decía:

El sujeto deficiente mental hace sólo 25 años era considerado tanto por los especialistas psiquiátricos como por el resto de los ciudadanos, como manicomiable, es decir, que todo aquel que se hallase en estas condiciones, más pronto o más tarde, acabaría con sus huesos en una institución o asilo destinado a la asistencia psiquiátrica (...) la atención, educación y tratamiento eran consideradas en nuestro país, tanto por las instituciones oficiales como por los propios especialistas psiquiátricos y profesionales en la educación, como "poco rentables" (...) lo que hacía que aquella función fuera encuadrada en el ámbito de la beneficencia. 
También dijo "el alcance real de la función de FEAPS: 'concienciar' a un pueblo indiferente e insensible"

Es obvio que los avances a la hora de desarrollar servicios, desde los más asistenciales y segregados a los que se ocupan de los anhelos y proyectos de vida de cada persona con propuestas inclusivas, han ido evolucionando de manera paulatina e inexorable. Lo veremos en el apartado de la evolución de los modelos de intervención. No obstante, hay que comprender que se produjo a partir de los años 80 una cierta "obsesión" por la normalidad, para que las personas fueran lo más normales posible, que vistieran lo más normal posible, que tuvieran la vida más normal. Entró de lleno el principio de normalización de Bank-Mikkelsen, que lo definió como "la posibilidad de que los deficientes mentales lleven una existencia tan próxima a lo normal como sea posible” y de W. Wolfensberger, que matizó la definición con la siguiente formulación:

Normalización es la utilización de medios culturalmente normativos (familiares, técnicas valoradas, instrumentos, métodos, etc.), para permitir que las condiciones de vida de una persona (ingresos, vivienda, servicios de salud, etc.) sean al menos tan buenas como las de un ciudadano medio, y mejorar y apoyar en la mayor medida posible su conducta (habilidades, competencias, etc.), apariencia (vestido, aseo, etc.), experiencias (adaptación, sentimientos, etc.), estatus y reputación (etiquetas, actitudes, etc.).

\section{La evolución de la ciudadanía de las personas con discapacidad intelectual o del desarrollo}

El ejercicio de la ciudadanía se ancla en tres ejes principales: los ciudadanos tienen derechos y obligaciones, los ciudadanos forman parte activa de la sociedad, están incluidos en ella, los ciudadanos están empoderados para ejercer su participación en la comunidad a la que pertenecen con libertad y para tomar decisiones sobre su vida. Así que los derechos (las condiciones legales y éticas), la inclusión (las condiciones sociales) y el empoderamiento (las condiciones personales) constituyen los elementos principales de la ciudadanía.

Así, a lo largo de la historia de estas décadas, se han ido produciendo expresiones cada vez más nítidas de las propias personas con discapacidad intelectual reivindicando su lugar en la vida y en la sociedad, buscando apoyos pero exigiendo, a la vez, un cambio en las actitudes paternalistas tanto de sus familias como de las organizaciones que les prestan servicios.

Los movimientos de autogestores en el mundo han sido en estos años un espacio de reflexión, deliberación y empoderamiento del colectivo y de sus miembros. En 1999, se realiza el primer encuentro de autogestores, antes denominados autodefensores, y paulatinamente van incrementándose los grupos que funcionan en FEAPS.

3 Intervención del primer presidente de FEAPS, Ernesto Puerto, en el vigésimo aniversario de 
el movimiento asociativo FEAPS. Alrededor de 5.000 personas con discapacidad intelectual son autogestores en el movimiento asociativo FEAPS.

\section{Muestras de empoderamiento}

En este marco, es muy importante reproducir el discurso que en 1992 presentó ante la Asamblea General de Naciones Unidas Barb Goode, una mujer con discapacidad intelectual, integrante del Consejo de la ILSMH, Liga Internacional de Asociaciones de Personas con Discapacidad Intelectual. Barb Goode dejó en el aire de la sala la emoción de sus palabras sencillas y contundentes que hicieron hincapié en los siguientes mensajes textuales ${ }^{4}$ :

¡Déjennos actuar!

Queremos avanzar en nuestros derechos y dar a conocer a los demás que estamos aquí. Sabemos que tenemos derechos, y también responsabilidades.

Queremos explicar a nuestros conciudadanos que somos capaces de vivir y trabajar en la comunidad.

Nuestra voz puede ser nueva para la mayoría de ustedes, pero sería bueno que se fueran acostumbrando a oírla.

Muchos de nosotros todavía tenemos que aprender a escucharnos y a entendernos.

Necesitamos a personas que crean en nosotros.

Tienen que comprender que a nosotros, como a ustedes, no nos gusta vivir en instituciones. Queremos vivir y trabajar en nuestras propias comunidades.

Contamos con su apoyo a las personas con deficiencia mental y a sus familias. Y con su apoyo a la Liga Internacional y a sus asociaciones miembros.

Sobre todo les pedimos que nos concedan el derecho a elegir y tomar decisiones sobre nuestra propia vida.

Estamos hartos y hartas de que las personas nos digan que hagamos lo que ellos quieren. En lugar de ello, ¡déjennos actuar como un equipo!

Todos nosotros tenemos que encontrar formas de ayudar a mis amigos que no son capaces de hablar.

Gracias por hacer posible que esté aquí y por escuchar lo que les digo en mi nombre y en el de las personas con discapacidad intelectual.

Y también fue importante la frase que, en la Asamblea General de FEAPS de 2001, pronunciaron dos representantes de los grupos de autogestores: "Queremos que nos representéis, pero siempre hasta cierto límite”. Las personas con discapacidad intelectual pidieron una mayor autorrepresentación y la están pidiendo ahora con mucha más fuerza. FEAPS está avanzando en ese sentido. En el Congreso de Toledo de 2010 una de las resoluciones votadas por unanimidad fue la de buscar fórmulas auténticas para que las personas con discapacidad intelectual estén en los lugares de las entidades en los que se toman decisiones. Así, en la Junta Directiva de la Confederación

4 Intervención de Barb Goode, una persona con discapacidad intelectual, en la Asamblea General de Naciones Unidas en 1992. 
una persona con discapacidad intelectual se ha incorporado en 2013, se han creado grupos guía de los proyectos estratégicos de FEAPS en los que participan personas con discapacidad y también se ha constituido el grupo de apoyo a la dirección de la confederación compuesto por personas con discapacidad.

En cualquier caso, algunos planteamientos científicos, unidos a las demandas de las propias personas, van ayudando a éstas a empoderarse en los servicios y en la comunidad. El principio de autodeterminación y las herramientas para desarrollarla son una muestra positiva de este maridaje.

\section{La defensa de derechos}

En todo caso, hay añadir los hitos de lucha por los derechos de estos años. Es más que reseñable la Declaración de los derechos generales y especiales del deficiente mental de Jerusalén de 1968, en el seno de la Liga Internacional, que posteriormente fue asumida por la ONU. El lema de la reunión de la Liga era "De la caridad a los derechos”. La declaración de Jerusalén fue una de las bases orientadoras principales para el movimiento asociativo en la década de los 70.

Fruto de la evolución cultural del sector, cada vez más basado en derechos, se llevaron a cabo manifestaciones públicas del movimiento asociativo como fue el caso de la quema de una hucha por parte de las asociaciones andaluzas en 1980 o la petición de la federación de asociaciones de Madrid al gobernador civil de Madrid, en 1981, de que prohibiera las cuestaciones públicas con huchas para pedir por los subnormales. El movimiento asociativo de Madrid y el de Andalucía estaban dispuestos a renunciar a los ingresos de las cuestaciones y dedicar toda su energía para que el sistema se estableciera sobre pilares de derechos.

2003 fue un momento muy importante para los derechos de las personas. FEAPS aprueba y publica su Código Ético. En él se recogen principios, valores y normas que pretenden garantizar los derechos y el trato digno de todas las personas con discapacidad intelectual en todas las organizaciones y en sus servicios.

El hito reciente más importante, en 2006, es la aprobación en Naciones Unidas de la Convención de Derechos de las Personas con Discapacidad y la ratificación del Gobierno de España de la misma. Es ésta una palanca clave para la defensa de los derechos que permite una argumentación clara y contundente en las reivindicaciones, tanto del movimiento asociativo como de las instituciones públicas o privadas que trabajan para mejorar la calidad de vida de este colectivo.

FEAPS, además, de manera muy especial en el Congreso de Toledo de 2010, después de la aprobación de la nueva Misión, ha introducido de manera muy intensa la línea estratégica de la defensa de los derechos y se han desarrollado muchas y significativas actividades que tienen valor, no sólo por su carácter operativo, sino también simbólico. El movimiento asociativo FEAPS puso de relieve en su diagnóstico que la extensa e intensa actividad de gestión y prestación de los servicios había debilitado la acción de la defensa de los derechos. 
Así que, en consecuencia, en 2011, FEAPS inició su primera campaña, “mi voto cuenta”, para reivindicar el derecho al voto de las personas con discapacidad intelectual que por sentencias de incapacitación se les niega el derecho a votar. Organizó la celebración del Año de la Ciudadanía en 2013, que concluyó con la presentación del Manifiesto por la plena ciudadanía en Cádiz en el Auditorio San Felipe Neri, cuna de la Constitución española de 1812, y que fue elaborado por grupos de autogestores de toda España. Promovió y organizó la formación de formadores en derechos a personas con discapacidad intelectual; estos formadores han intervenido en actividades formativas a personas con discapacidad, a profesionales, a juntas directivas... Ha desarrollado métodos de redacción y evaluación de Lectura Fácil para hacer accesibles documentos que son de interés para las personas. Organizó la exposición itinerante "Con otra mirada”, que ha recorrido toda España, con la historia de los derechos de las personas con discapacidad intelectual en el mundo.

Una mirada inclusiva

El acto de Cádiz con el Manifiesto de la Plena Ciudadanía y la exposición itinerante suponen un enorme impulso a la regeneración moral y ética de nuestro movimiento asociativo porque ayuda a aprender y exige mirar de otra manera, a ver a las personas con discapacidad intelectual de otra manera, desde otro ángulo diferente al tradicional.

Pero, cuando se habla de cambio de mirada ¿a qué nos referimos?, ¿en qué consiste eso del cambio de mirada? ${ }^{5}$.

Cambiar la mirada significa (ha de significar) mirarnos a nosotros mismos mirando a las personas con discapacidad intelectual de otra manera. Hemos de observarnos y analizar nuestra forma de mirar. Significa individualizar y mirar a cada persona y no al colectivo. La definición de las personas por las supuestas características del colectivo al que pertenecen suele ser una agresión. La agrupación lleva a la simplificación y, por tanto, a la desfiguración. Los clichés y las imágenes ficticias nos ocultan los tesoros que lleva dentro cada persona. Cambiar la mirada significa cambiar las creencias; de una mirada sobreprotectora y superior, y siempre dispuesta a sorprenderse de "lo que son capaces de hacer", saldrá una práctica de empoderamiento y de inclusión bienintencionada, pero raquítica y limitada.

Significa entender que todos los seres humanos necesitamos de los demás para ser nosotros mismos. Con la mirada de los otros, de su espejo, nos construimos. Con lo que nos devuelven las personas a las que queremos y respetamos, forjamos nuestro carácter. Cambiar la mirada hacia las personas con discapacidad intelectual o del desarrollo supone y significa creer y experimentar que su mirada sobre nosotros es importante para construirnos, para hacernos mejores, para comprender mejor nuestros sentimientos y emociones, nuestros egoísmos, miedos, alegrías, escudos y disfraces.

5 Lacasta, J. J. (2012). Cádiz, cruce de miradas. Conectados. http://conecta2.feaps.org/blogs/5fe4fbf8422b-43f3-bfce-66c7b4793437/?sortby=0\&maxresults=25\&page=1\&lang=es_es. 
Cambiar la mirada significa que necesitamos también a personas con discapacidad intelectual y a otras en situación de exclusión para que nos ayuden a ser nosotros mismos. Que nos importe cómo nos mira una persona con discapacidad intelectual o del desarrollo supone emprender el camino de llegar a creer profundamente en su dignidad en la práctica, no sólo en el discurso.

Que nos importe la mirada de una persona con discapacidad intelectual, no sólo su cariño, significa empezar a desdibujar la poderosa línea convencional creada entre quien tiene y no tiene discapacidad intelectual y dejar de hablar de ellos y nosotros. Además, cambiar la mirada hacia las personas con discapacidad intelectual significa un enriquecimiento personal de tal calibre que supone y lleva implícito el cambio de mirada para cualquier ser humano y el cambio, tan necesario, hacia la humildad y la igualdad.

Si comprendemos la importancia de la mirada de las personas con discapacidad intelectual o del desarrollo y de lo que ésta nos devuelve, no tendremos ningún obstáculo para ver a las personas con toda su dignidad, verdaderamente activas, ciudadanas y protagonistas de su vida y... de la nuestra.

\section{Los modelos de intervención}

Los cambios de los paradigmas científicos y de los modelos de intervención han sido muy acentuados. Y FEAPS ha ido no sólo observando, sino participando en las propuestas y en la aplicación efectiva de las propuestas científicas y metodológicas que a lo largo del tiempo han venido apareciendo.

Por poner algún botón de muestra sobre cómo han ido influyendo los modelos en distintos ámbitos, ya en 1973, en la 1. Jornada Nacional de Asistentes Sociales, éstos concluyeron que "el asistente social debe trabajar partiendo de un criterio de normalización, defendiendo al máximo este principio en todas sus actuaciones profesionales”. En 1981, En la declaración de Torremolinos del Año Internacional del Minusválido, se concluyó: "Los poderes públicos, la sociedad y las organizaciones competentes tendrán en cuenta al elaborar toda estrategia respecto a las personas disminuidas, los principios básicos de participación, normalización, integración, personalización, sectorización y multiprofesionalidad".

Un punto interesante de observación de la evolución de los modelos son los cambios en las formas de evaluar y diagnosticar y en las distintas definiciones y clasificaciones de la discapacidad intelectual. Para hacer un recorrido muy simplificado, en 1963 a una madre le dieron el diagnóstico de su hija de "mongolismo frustrado" 6 más adelante se clasificaba a las personas en subnormales profundos, severos, medios, moderados y ligeros. En 1980 la OMS publicó la CIDDM, la Clasificación Internacional de Deficiencias, Discapacidades y Minusvalías y la CIF, la Clasificación del Funcionamiento, de la Discapacidad y de la Salud en 2001.

6 Carta de Elena Saiz, madre de Elena Gómez. Las asociaciones son estupendas. Te arropan y hacen que no te sientas sola. LÓPEZ, J. (2014). FEAPS 50 ANIVERSARIO. 50 años con las personas con discapacidad intelectual. FEAPS. 
No obstante, las definiciones y clasificaciones que han tenido más impacto en FEAPS, en sus entidades y servicios, han sido la Definición de Retraso Mental, clasificación y sistema de apoyos de 1992 de la Asociación Americana para el Retraso Mental (AAMR) y sus revisiones de 2002 y 2010. En el Congreso de Toledo de 1996, en el que se aprobó la Misión del movimiento asociativo FEAPS: “mejorar la calidad de vida de las personas con retraso mental y la de sus familias”, se adoptaron, como guía propia para el cumplimiento de la misión y para la orientación de los servicios, la Definición de Retraso Mental de la AAMR, basada en el funcionamiento de la persona, su relación con el entorno y en el paradigma de apoyos; y más adelante, de manera complementaria a la definición, el Modelo de Calidad de Vida de Schalock y Verdugo de 2002/2003 con sus ocho dimensiones: bienestar emocional, bienestar físico, bienestar material, desarrollo personal, autodeterminación, relaciones interpersonales, inclusión social y derechos.

Así que, a lo largo de la historia de FEAPS, los modelos y, de acuerdo con ellos, las estrategias de intervención han ido cambiando significativamente. Es destacable el tránsito desde la idea de que los subnormales eran sólo adiestrables a la educación especial, pasando por la integración escolar hasta la lucha actual por la educación inclusiva. Más destacable, si cabe, es la evolución de las fases del desarrollo de los servicios (Valery Bradley, 1994): del modelo institucional, pasando por el modelo de integración al modelo de inclusión o de ciudadanía. Por describir los modelos de manera muy simplificada, en el modelo institucional quien recibe el servicio es el paciente, se planifican sus cuidados, toma las decisiones el especialista, guían los principios de atención: limpieza, salud y seguridad, y la calidad se mide por la práctica profesional de los cuidados; en el modelo de integración quien recibe el servicio es el cliente, lo importante es la adquisición de habilidades, toma las decisiones el equipo multidisciplinar, guía el principio de socialización y la calidad se mide por la realización de programas y cumplimiento de objetivos; en el caso del modelo de inclusión, quien recibe el servicio es el ciudadano, lo que se planifica es el futuro de la persona, toma las decisiones su círculo de apoyo, guían los principios de autodeterminación, de relaciones y de inclusión y la calidad se mide por el incremento de la calidad de vida del individuo.

Así que actualmente los servicios están, cada uno en mayor o menor medida, en el tránsito entre el asistencialismo y el modelo de calidad de vida. Y en este camino se han ido desarrollando numerosas estrategias, herramientas y escalas para conocer las necesidades de apoyo de las personas o para evaluar el impacto de los apoyos en las dimensiones de calidad de vida. Son especialmente valiosas la Escala de Intensidad de Apoyos (SIS), la Escala INICO/FEAPS de Evaluación integral de la Calidad de Vida o la Escala San Martín de Evaluación de la Calidad de Vida de Personas con Discapacidades Significativas. Asimismo, para desarrollar planes personales, la planificación centrada en la persona en los últimos tiempos ha sido una estrategia y una herramienta especialmente valiosa que tiene importantes consecuencias, si se aplica en profundidad, en el cambio organizacional. 
La evolución de los servicios en FEAPS

FEAPS, el movimiento asociativo que representa, ha tenido un protagonismo muy especial en la gestión de los servicios de apoyo a las personas con discapacidad intelectual. La inmensa mayoría de los servicios en España son gestionados por las entidades de FEAPS, desde hace más de 50 años. El movimiento FEAPS da apoyos a más de 140.000 personas a través de 4.000 servicios. El esfuerzo ha sido monumental.

FEAPS, a partir del Congreso de Toledo 1996, abrazó el modelo de calidad de vida y los modelos de inclusión y se puso manos a la obra. Desplegó un conjunto de estrategias para introducir técnica, ética y apoyos al cambio organizacional. Gracias a esas estrategias hay casi 300 organizaciones que de una manera u otra están desarrollando procesos de transformación. Han sido muy importantes las siguientes:

- La elaboración con los propios profesionales de las entidades de FEAPS y la publicación de los 8 Manuales de Buena Práctica en el año 2000 sobre los distintos ámbitos de servicios: atención temprana, educación, ocio y vida social, promoción laboral y empleo, atención de día, vivienda y residencia, apoyo a familias y asociacionismo.

- La elaboración participada y la publicación del Código Ético de FEAPS en 2003. Un código de ética profesional, familiar e institucional.

- La elaboración del Modelo de Calidad FEAPS y la elaboración y puesta en marcha del Sistema de Evaluación de la Calidad FEAPS, lanzado para su aplicación y uso en 2006. Es un modelo que se equilibra asentándose en tres ejes sobre los que hay que mostrar evidencias: calidad de vida, calidad de gestión y ética. Es un sistema que se certifica por un comité de acreditación y que cuenta con 4 niveles: compromiso, despliegue, calidad y excelencia. En este tiempo se han certificado medio centenar de entidades.

- La apuesta por la formación de expertos en calidad de vida a través del Máster coorganizado con el Instituto de Integración en la Comunidad (INICO) sobre Integración de Personas con Discapacidad. Calidad de Vida. En las distintas ediciones, se han formado en este máster más de 100 profesionales de entidades de FEAPS de toda España y constituyen una red para apoyar proyectos vinculados a este saber.

- Las 5 ediciones de Buenas Prácticas con sus correspondientes publicaciones, desde 2002, hasta la actualidad. Se han puesto en valor cientos de buenas prácticas, valoradas por un comité independiente.

- La elaboración y edición del Modelo de Política de Personas -de recursos humanos-de FEAPS en 2007 y la guía metodológica para que las entidades puedan desarrollar sus propios Planes de Personas y la puesta a disposición de un sistema de apoyo a las entidades para ello. Hay 130 entidades involucradas en Planes de Personas.

-- El desarrollo de Proyecto de Dinamización Asociativa que propicia la renovación asociativa y la participación de las personas y de las familias en las entidades y el ejercicio de un liderazgo participativo. El año 2013 fue el Año de la 
Participación de FEAPS. Es de resaltar también la Escuela de Directivos que ha formado ya a más de 1.000 directivos sociales.

- El desarrollo del Proyecto de Transformación de Entidades y Servicios para la Calidad de Vida. Aprobado en 2010 y desarrollándose en los últimos 4 años. Se ha elaborado el Modelo de Servicio Centrado en la Persona en 2014 y se han iniciado procesos de transformación en las siguientes áreas: ocio inclusivo, atención temprana, centros ocupacionales, buena vejez, la educación que queremos. Se han involucrado en procesos compartidos de cambio y de aprendizaje en común un centenar de servicios. Para 2015, está previsto iniciar procesos de transformación en los ámbitos de ocio inclusivo (segunda fase), el hogar que queremos y la atención de día que queremos.

- La formación para todos los grupos de interés y la gestión del conocimiento y de buenas experiencias a través de herramientas como la intranet FEAPS.

\section{Las familias: la evolución de sus derechos y de su rol}

La mentalidad y el papel de la familia también han ido variando a lo largo de estos años. Los primeros fueron duros para las familias, por la soledad, por la incomprensión social, por la estigmatización que tener un hijo subnormal suponía, por los sentimientos tan negativos que muchas familias decían tener (las que lo decían): culpa, vergüenza..., por el aislamiento social, por la necesidad más de esconder que de mostrar, por la sobrecarga sin apoyos y servicios ningunos.

La unión inicial entre familias propiciada por los más osados y valientes que buscaban otras familias, casa por casa, en los años 50 y 60, y la constitución de asociaciones supuso un vuelco en la manera de entender y afrontar los problemas; supuso pasar de la vergüenza a un rol de lucha y de apoyo mutuo. El impulso de servicios y de políticas por parte de las asociaciones de familiares ha sido, en las últimas décadas, heroico. Asumieron un rol reivindicativo, voluntario y emprendedor, claves para el progreso de este país. Fueron profesionalizando las entidades y los servicios y las familias se fueron retirando poco a poco de la participación asociativa y fueron adquiriendo un mero papel de clientes o consumidores de servicios. Fue debilitándose su sentido de pertenencia y su energía reivindicativa y promotora. En la actualidad FEAPS está tratando de revertir esa situación y está desarrollando estrategias para empoderar a las familias, para hacerlas protagonistas de la inclusión de sus hijos y para que participen activamente en las asociaciones a las que pertenecen.

El Congreso de Toledo de FEAPS de 1996 tuvo una importancia especial para las familias de las personas con discapacidad intelectual. El movimiento asociativo de toda España acordó la siguiente formulación de la Misión: "Mejorar la calidad de vida de las personas con retraso mental y la de sus familias". Por primera vez en la historia de FEAPS se integraba a las familias como destinatarias últimas de la Misión. Siempre habían sido contempladas únicamente como parte coadyuvante en la mejora de la atención de las personas con discapacidad y como base social de las asociaciones en favor de las personas con discapacidad intelectual, pero no como destinatarias de servicios y apoyos. 
Tradicionalmente, se habían dirigido los esfuerzos y los recursos hacia la habilitación y rehabilitación de la persona con discapacidad, no hacia la familia de la persona con discapacidad. Ni siquiera el movimiento asociativo de composición mayoritariamente familiar había prestado atención a las familias. Éste era un movimiento "de" familias, pero que no lo era "para" las familias. Las familias tienen necesidades propias por el hecho de tener un miembro con discapacidad intelectual, que son distintas de las que tienen sus miembros con discapacidad. Se ponen en evidencia las necesidades de apoyo que precisan las familias para mejorar su propia calidad de vida, como, desde una perspectiva sistémica, para mejorar la calidad de vida y las oportunidades de sus miembros con discapacidad'

A lo largo de estos 50 años los avances logrados para las familias han ido dirigidos a dos líneas principales: derechos de protección familiar y apoyos y servicios para las familias. En la primera línea, aunque este país nunca ha alcanzado los niveles de protección familiar de la media europea, se pueden destacar los siguientes hitos históricos, basados en las reivindicaciones del movimiento asociativo: en 1963 se reivindicó, sin éxito, en las Primeras Jornadas Técnicas de FEAPS medidas para ampliar el concepto de familia numerosa, solicitando que "un subnormal equivaliese a 4 normales". Sí fue un éxito importante el decreto de la Seguridad Social de 1968 que otorgaba una prestación de 1.500 pesetas mensuales por cada hijo con discapacidad; otro avance posterior fue la prestación por hijo a cargo; o la ampliación del concepto de familia numerosa de 1998, considerándose familia numerosa a aquella con dos hijos si uno de ellos tenía discapacidad.

En los últimos años se han realizado en FEAPS estudios muy importantes para defender los derechos de protección de las familias: en 2006 se hizo el primer estudio sobre el sobreesfuerzo económico que las familias tienen que afrontar por tener un hijo con discapacidad intelectual y en 2014 se ha presentado el segundo. En la actualidad no hay prestaciones públicas suficientes ni servicios que cubran el sobreesfuerzo que una familia tiene que hacer. El otro estudio es sobre el impacto del copago en los servicios en las familias con hijos con discapacidad intelectual: el copago supone para muchas familias la expulsión del sistema de servicios sociales. Los dos estudios son dos instrumentos rigurosos que van a ayudar a FEAPS a argumentar las reivindicaciones en ese sentido.

En relación a la segunda línea de prestación de apoyos y servicios los esfuerzos y actividades desarrolladas por FEAPS han sido desde 1993 muy importantes:

- En 1993 se desarrolla el primer Programa de Apoyo a Familias, financiado por los fondos del 0,5\% del IRPF, con 3 federaciones: Madrid, Navarra y Murcia. A partir de ese año, se incorporan el resto de las comunidades autónomas y se ha desarrollado todos los años hasta la actualidad. El programa ha conllevado actividades como las siguientes: formación de padres, apoyos padre a padre, guías de orientación, distintas modalidades de respiro, jornadas, congresos, etc.

7 Conferencia "Calidad de los servicios de apoyo familiar" de Juan José Lacasta en el primer Congreso Nacional de Personas con Retraso Mental. 2000. 
Actualmente el Programa de Apoyo a Familias, cuantitativamente, es el más dotado de FEAPS por los fondos de la asignación tributaria del IRPF.

- Se celebran, desde el año 2000, cinco congresos de familias y varios encuentros.

- Se elabora y publica en 2004 el modelo de Servicio de Apoyo a Familias.

- Se han ido creando en algunas comunidades autónomas servicios específicos de Apoyo a Familias.

- En los últimos años se está impartiendo un Máster en colaboración con la Universidad Autónoma de Madrid sobre Calidad de Vida Familiar.

- Desde 2011 se ha puesto a disposición de las familias la red social Conecta2.

- En 2011 se elabora el Modelo de Calidad de Vida Familiar en colaboración con la Universidad Ramón Llull de Barcelona.

\section{El Movimiento Asociativo FEAPS y su proyecto común}

\section{La evolución de FEAPS}

Las organizaciones que pertenecen al movimiento asociativo FEAPS son asociaciones, fundaciones, cooperativas y otras entidades jurídicas, todas ellas sin ánimo de lucro. Son 884, más las federaciones autonómicas que integran dichas organizaciones. Estas entidades gestionan servicios y proyectos y programas para la calidad de vida de las personas con discapacidad intelectual y la de sus familias.

La evolución histórica de FEAPS, desde un punto de vista organizativo, ha sido la siguiente:

En 1964 nace la Federación Española de Asociaciones Pro Subnormales, con 19 asociaciones. En 1967 ya cuenta con 69. Nace con el claro objetivo de la unidad y de ser representante ante los poderes públicos de, entonces, la dictadura. En 1970 se crean dos medios de comunicación de FEAPS: el boletín VOCES, más para contar temas de actualidad, y otro boletín más reflexivo y con monográficos que posteriormente sería la revista científica de FEAPS: SIGLO CERO ${ }^{8}$. En 1974, FEAPS, en colaboración con la Fundación General Mediterránea, crea la Mutualidad de Previsión Social de Ayuda a Subnormales, una mutualidad para asegurar una pensión a las personas con discapacidad intelectual cuando faltaran sus padres.

En 1977 se crea la primera federación autonómica, la de Castilla y León, y se van creando todas las demás en todas las autonomías hasta el año 2000. Se vertebra así el movimiento asociativo adaptándose al Estado de las Autonomías instaurado en la Constitución española de 1978. Y FEAPS, en 1984, pasa de ser una federación a ser una confederación. Éste fue un proceso de anticipación clave, para asegurar la interlocución de FEAPS con los Gobiernos de las autonomías. En 1993, FEAPS desarrolla un proceso para cambiar la imagen y adquirir una nueva identidad corporativa. Es

8 Se le llamó Siglo Cero porque a juicio de los directivos de entonces se estaba en el siglo cero de la deficiencia mental. 
un proceso que ayuda a tener una imagen compartida y un mayor sentido de unidad porque las federaciones adquieren la misma imagen y también muchas entidades.

En 1995 FEAPS promueve la constitución de la Asociación Española de Fundaciones Tutelares, para agrupar y coordinar la tarea de este tipo de fundaciones que fueron promovidas, en su mayoría, por las federaciones y por algunas entidades para garantizar la tutela de personas con discapacidad, incapacitadas judicialmente, que se quedaban sin padres o tutores familiares. Se articula la función tutelar a través de esta asociación. En 1995 se crea la Asociación FEAPS para el Empleo de las Personas con Discapacidad Intelectual (AFEM), una asociación patronal que reúne los Centros Especiales de Empleo y entidades dedicadas al empleo de FEAPS. Con AFEM se articula la función reivindicativa sobre los derechos de empleo de las personas y de la generación de sinergias entre las entidades dedicadas al empleo.

Pero el avance más importante se produce con el Congreso de Toledo de 1996 (FEAPS Siglo XXI). A través de 10 ponencias elaboradas por 10 equipos que fueron contrastadas en 10 seminarios y dialogadas en las entidades de FEAPS, se establece el diagnóstico del movimiento asociativo FEAPS y se plantean las líneas estratégicas de futuro. Participan en el proceso del congreso más de 1.000 personas, es el primer proceso masivo de participación que desarrolla FEAPS y las personas que lo vivieron manifestaron que el congreso marcó un antes y un después en la historia del movimiento asociativo FEAPS. Las ponencias trataron los siguientes temas: la persona con retraso mental; la misión; la integración, el sentido de pertenencia; el papel de los dirigentes; la atención al cliente y la calidad del servicio; la política de financiación; la adaptación al entorno; las estrategias de relación con otras entidades; la planificación, el control y los sistemas de trabajo; y el diseño organizativo. Hubo conclusiones muy importantes en todos los temas pero fueron cruciales para el futuro los siguientes: se acordó una Misión -hasta el congreso no había una misión compartida-, fue: "Mejorar la calidad de vida de las personas con retraso mental y la de sus familias", incluyendo al colectivo de familiares en la misma; se acordaron los valores; se adoptó la Definición de Retraso Mental de la AAMR, el marco de calidad de vida y la calidad como sistema de gestión. Las conclusiones dieron lugar a la elaboración y aprobación del Primer Plan Estratégico de FEAPS orientado en torno a los siguientes ejes estratégicos: las personas con retraso mental y el proceso cultural, el plan de calidad, el plan de comunicación, un plan para la eficiencia, el desarrollo organizativo y el liderazgo en el entorno.

El desarrollo organizativo, fruto del congreso, fue claro y evidente. Se crearon las Unidades de Desarrollo Sectorial (UDS), tanto a nivel estatal como autonómico. Eran redes de personas expertas en temas y servicios: empleo, educación, atención temprana, vivienda, etc. Se creó la red de responsables de comunicación de las federaciones en 1998, la red de calidad en 2001 y funcionaron multitud de grupos de trabajo vinculados a programas y proyectos.

La Red de Calidad, con miembros en cada una de las federaciones, se ha encargado de impulsar el Sistema de Evaluación de la Calidad FEAPS, en sus correspondientes entidades. Ha elaborado el modelo de calidad y el sistema de evaluación, ha formado y orientado a los responsables de las entidades y ha organizado jornadas de buenas 
prácticas tanto a nivel estatal como autonómico. La calidad FEAPS es un eje de vertebración cultural, técnica y organizativa que ha sido clave tanto para la orientación de los servicios a las personas, como a la conformación del proyecto común en claves compartidas.

En 2001, se pone en marcha la Red de Consultoría. Se crea con profesionales de entidades y federaciones de FEAPS que cursan el Máster de Consultoría y Gestión de Procesos de Desarrollo Organizacional de la Universidad de Valladolid y que gracias a este máster pueden ejercer como consultores de organizaciones. La red se constituye con la siguiente misión: "Facilitar al movimiento asociativo FEAPS -a sus entidades y estructuras-, apoyos para un desarrollo organizacional coherente con su misión, visión y valores”. Desde su creación, el servicio que da la red, ha intervenido en más de 120 demandas de entidades y federaciones de FEAPS relacionadas con planificación estratégica, desarrollo de equipos de dirección, implantación de la Calidad FEAPS, selección de gerentes, conflictos organizacionales, diseños organizativos, etc. Además la Red de Consultoría ha apoyado procesos internos de la confederación de configuración de redes y equipos, apoyos a proyectos nuevos, etc. La red la constituyen actualmente más de 50 consultores.

En 2005 se crea el Comité de Ética con la misión de "Ayudar al Movimiento Asociativo FEAPS, a través de sus actuaciones, a generar comportamientos institucionales, organizativos y personales cada vez más coherentes desde el punto de vista ético y a asumir la responsabilidad de incorporar el debate ético en la resolución de sus conflictos”. Entre sus funciones están: emitir dictámenes; ofrecer orientaciones para tomas de postura en procesos de decisión en los que aparecen dudas o conflictos éticos; y elaborar protocolos de actuación ética para las situaciones problemáticas que resulten habituales; también pueden proponer modificaciones para el Código Ético.

Después del Congreso de Toledo de 1996 se han celebrado Foros Asociativos, con la participación de 500 personas en cada uno, en Sevilla, en 2001, con el lema “Asociaciones, cambio y calidad de vida" y en 2005, en Oviedo, con el lema "Juntos, otro mundo es posible”. En ambos foros se hizo una valoración del plan estratégico que finalizaba y se hizo diagnóstico de la situación y se plantearon las líneas de futuro para los años siguientes. Así de Sevilla nació el II Plan Estratégico y de Oviedo, el tercero. La evolución estratégica de FEAPS en esos años ha sido clara: incremento del protagonismo y del poder de las personas con discapacidad intelectual; incremento del sentido de proyecto común -la visión de futuro que presentó la Junta Directiva en el Foro de Oviedo fue: “Queremos ser una organización unida”-; y mayor influencia en el entorno.

Si el Congreso de Toledo de 1996 supuso un antes y un después, el de Toledo de 2010, con el lema "Por lo que nos une", fue un punto de inflexión determinante para el Proyecto Común de FEAPS. Primero porque el congreso duró un año a lo largo del cual participaron 7.500 personas y 428 entidades de FEAPS. De las más de 10.000 aportaciones generadas en ese proceso se elaboraron, por equipos, 6 ponencias: la Misión del Movimiento Asociativo FEAPS, las personas con discapacidad intelectual y las familias, el poder y la participación, el asociacionismo, el modelo organizativo y las relaciones de FEAPS con el entorno. 
Se presentaron en febrero de 2010 en Toledo las propuestas de las ponencias y las propuestas alternativas ante 500 delegados, se debatieron y se votaron. De ahí salieron 33 resoluciones aprobadas con más de dos tercios de los votos. La resolución más importante fue la nueva misión de FEAPS: “Contribuir, desde su compromiso ético, con apoyos y oportunidades, a que cada persona con discapacidad intelectual o del desarrollo y su familia puedan desarrollar su proyecto de calidad de vida, así como promover su inclusión como ciudadana de pleno derecho en una sociedad justa y solidaria”, mucho más comprometida que la anterior porque pide a las entidades que tienen que adquirir competencias para los temas principales que apunta la misión.

La misión conecta con los paradigmas científicos y sociales más avanzados y requiere de una renovación organizativa, de la innovación y el conocimiento a todos los niveles. Está presente la individualización de los apoyos, el empoderamiento de las personas, la búsqueda de la inclusión, la necesidad de hacer un mundo mejor, la ética... Son objetivos que para ser acometidos hay que querer afrontarlos, saber hacerlo y poder hacerlo.

Hay otras resoluciones clave como la implantación de la calidad FEAPS como requisito de pertenencia, o la participación de las personas con discapacidad en los lugares donde se toman decisiones, o la incidencia política o las alianzas con otros actores de lo social, o el cambio de nombre de FEAPS, o el desarrollo de la participación a todos los niveles, o la implicación definitiva en la defensa de los derechos de las personas y de sus familias, o la apuesta decidida por la inclusión, o el cuidado de los profesionales y los voluntarios, o abrir un camino mucho más profundo en la gestión del conocimiento...

A partir de Toledo 10, FEAPS ha seguido avanzando: se ha creado una red de juristas para defender mejor los derechos de las personas, se ha elaborado el IV Plan Estratégico con 10 proyectos estratégicos diferenciados, según se aprecia en la siguiente figura:

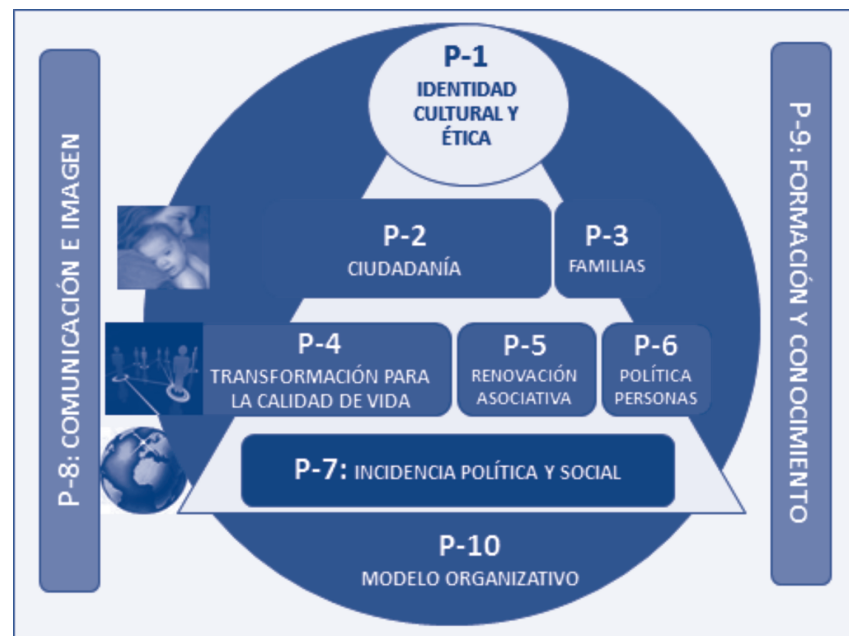

(C) Ediciones Universidad de Salamanca

Siglo Cero, vol. 46 (1), n. ${ }^{\circ} 253,2015$, enero-marzo, pp. 41-65 
Cada proyecto está orientado por un equipo guía transversal en el que están incluidos todos los roles del movimiento asociativo, incluidas personas con discapacidad intelectual. Todos los proyectos han tenido en los últimos cuatro años resultados significativos que se han ido reseñando en otros apartados de este artículo, pero es de destacar la aprobación por la Asamblea del nuevo Diseño Organizativo del Movimiento Asociativo de FEAPS sobre todo en lo que se refiere a la articulación entre la confederación y las federaciones y la aprobación de los nuevos estatutos de FEAPS.

\section{FEAPS y el entorno}

El movimiento asociativo FEAPS está en el entorno. Para ser más exactos está en muchos entornos: en la sociedad civil, en el tercer sector, en la relación con las administraciones públicas y también con las empresas del mercado.

El papel de FEAPS con los poderes públicos ha sido muy importante para la vida de las personas con discapacidad intelectual y para la de sus familias. Ha estado siempre cerca de la evolución legislativa, vigilante en el desarrollo de las políticas sociales y proactiva en la negociación y la reivindicación.

En España, la historia reciente de los derechos y de los servicios para las personas con discapacidad intelectual es coetánea y coincidente en el tiempo con la historia de FEAPS. Antes de FEAPS había manicomios, asilos y obras de beneficencia y miles de personas sin atención o abandonadas y no había derechos ni cauces administrativos para exigir nada.

Por eso, en 1963, ante la ausencia de recursos y de derechos, en las históricas primeras Jornadas Técnicas sobre los Niños Subnormales, se incluyen, entre las conclusiones, estas recomendaciones:

1: Se intentará promover en todo el territorio nacional Asociaciones de Padres y Protectores de Subnormales u otros deficientes, a los efectos de constituir vehículos por los cuales llegue a los poderes públicos la inquietud en torno al problema, y sean, a su vez, instrumento de solidaridad entre las familias afectadas. Y 2: Las diversas Asociaciones Provinciales, Comarcales o Locales de Padres y Protectores de Subnormales y otros deficientes deberán agruparse en una Federación Nacional que, adherida a la Delegación Nacional de Asociaciones, tendrá personalidad jurídica propia e independiente y será el órgano nacional supremo de enlace entre las Asociaciones que la constituyan y la Administración Pública en todas sus esferas.

Constituida FEAPS en 1964, a lo largo de su trayectoria y posteriormente constituida en confederación ha tenido intervenciones con las administraciones y poderes públicos de alta significación en la construcción de los derechos de las personas con discapacidad, no sólo intelectual.

En 1971 se crea el SEREM (Servicio de Recuperación y Rehabilitación de Minusválidos) que luego se reconvertiría en el INSERSO (Instituto Nacional de Servicios Sociales) -en 1980 FEAPS firma un convenio con el INSERSO para apoyar a las asociaciones en su labor de integración-. Posteriormente el INSERSO sería el IMSERSO

(C) Ediciones Universidad de Salamanca

Siglo Cero, vol. 46 (1), n. ${ }^{\circ} 253,2015$, enero-marzo, pp. 41-65 
(Instituto de Migraciones y Servicios Sociales). En 1974 se crea el Instituto Nacional de Educación Especial y en 1976 el Real Patronato de Atención y Educación de Deficientes. En 1977 se aprueba el Plan de Prevención de la Subnormalidad. En 1978 se aprueba en referéndum la Constitución española y el artículo 43 recoge los derechos de las personas con discapacidad. FEAPS influye en dicha incorporación, a la vez que, en el mismo año, envía un duro escrito al Gobierno diciendo que "la Administración, con la regresividad de la financiación, niega derechos a los subnormales: a nacer sanos -no se ha puesto en marcha el Plan de Prevención-, a la atención temprana, a la educación...” y sale a la calle en manifestación.

También en 1978 se aprueba el Plan Nacional de Educación Especial integrando la educación especial en la Enseñanza General Básica y en 1982 se aprueba la Ley de Integración Social del Minusválido (LISMI) con la intención de garantizar la realización personal y la total integración social de las personas con discapacidad. FEAPS acompaña e incide en el proceso de elaboración y en el de enmiendas a la Ley. Es la ley más importante porque se puede decir que ya hay un marco legal estructurado sobre el que construir los servicios sociales y la promoción del empleo de las personas con discapacidad. La LISMI supone una base principal para la creación por parte de las organizaciones de FEAPS de servicios sociales financiados con fondos públicos, la creación de centros especiales de empleo, la cobertura del $2 \%$ de los puestos de trabajo para las empresas con más de 50 trabajadores...

En 1983 se reforma el Código Civil en materia de Tutela y permite que instituciones puedan tutelar a personas que no tienen a nadie que lo haga. A partir de aquí se empiezan a crear las Fundaciones Tutelares con el impulso del movimiento asociativo FEAPS. En 1985, se publica el Real Decreto de Ordenación de la Educación Especial que establece que será obligatoria y gratuita y se establecen las bases para la integración escolar. Y también el Real Decreto por el que se regula la relación laboral de carácter especial de los minusválidos. En 1988 se regula el 0,5\% del IRPF para fines de interés social, lo que supone una vía muy importante para el desarrollo de programas de FEAPS: ocio, apoyo a familias, adultos solos, reclusos y exreclusos, personas en desventaja social, autogestores, apoyo al voluntariado, etc. FEAPS se integra, desde el inicio, en el Consejo Estatal de ONG, presidido por el Gobierno, que se crea una vez queda regulado el 0,5\% del IRPF.

2006 es otro hito en la legislación española con la promulgación de la Ley de Autonomía Personal y Atención a la Dependencia. Por fin se lograban prestaciones de derecho para las personas en situación de dependencia. FEAPS también estuvo atenta a esta ley. Los primeros borradores ignoraban las necesidades por dependencia de más del $80 \%$ de las personas con discapacidad intelectual. La intervención de FEAPS invirtió el porcentaje: se podrían beneficiar de las prestaciones de la ley hasta el 80\%. No obstante, con la crisis y la política de los recortes sociales, la ley ha quedado, en la práctica, casi sin efecto, generando situaciones insostenibles para muchas personas y muchas familias.

FEAPS en los últimos 4 años ha mantenido frente a las administraciones públicas una actitud de reivindicación exigente clamando por que no diera un paso atrás en los derechos alcanzados: constituyó un gabinete de crisis, ha apoyado las movilizaciones

(C) Ediciones Universidad de Salamanca

Siglo Cero, vol. 46 (1), n. ${ }^{\circ} 253,2015$, enero-marzo, pp. 41-65 
que se han dado en las diferentes comunidades autónomas, ha planteado reivindicaciones ante las elecciones generales de 2011, organizó una movilización en toda España en 2012, ha planteado propuestas ante las fórmulas de copago que plantea el Gobierno, ha trabajado con el CERMI para ello...

Por otra parte, más allá de la administración pública, FEAPS ha ejercido un papel intenso en la construcción del Tercer Sector: desde su inicio FEAPS se integra en la Liga Internacional de Asociaciones (ILSMH), posteriormente denominada Inclusion International y, en cuanto se crea, en Inclusion Europe. Participa en 1988 en la constitución de la Fundación ONCE y forma parte de su patronato desde el inicio (la colaboración de la Fundación ONCE ha sido determinante para apoyar los desarrollos que ha realizado FEAPS). En 1993 FEAPS forma parte del acuerdo de constitución del Comité Español de Representantes de Minusválidos (CERMI) y su primer presidente es Alberto Arbide, expresidente de FEAPS, participando activamente en la directiva y en las comisiones de trabajo y en los CERMI autonómicos. En 2000 FEAPS también participa en la creación de la Plataforma de ONG de Acción Social y en su construcción y colabora en sus comisiones y grupos de trabajo, y, más recientemente, a través del CERMI, en la constitución y estructuración de la Plataforma del Tercer Sector.

De otro lado, en relación con las empresas, la cooperación con éstas no ha sido temprana pero sí creciente, desde que se han comenzado colaboraciones enmarcadas en programas de responsabilidad social. En este marco, con espíritu de encuadrar las estrategias de responsabilidad social, FEAPS ha elaborado y aprobado un Modelo de Responsabilidad Social para que sirva de apoyo a las federaciones y entidades miembro, con la pretensión no sólo de obtener recursos, sino de establecer relaciones estables mutuamente satisfactorias en un marco ético, responsable y sostenible.

Otra faceta de la gestión del entorno que ha desarrollado FEAPS ha sido todo lo relacionado con la concienciación social. Desde su inicio ha llevado a cabo campañas como la del día del subnormal desde 1968; en 1972 el lema del día fue "Ayúdame a seguir". Todos los años se organizaron las semanas de información sobre las personas con discapacidad intelectual celebrándose en el mes de abril. Dejaron de celebrarse en 1987 porque se consideró que la información debe estar todos los días en la calle. En épocas más cercanas, instrumentos como VOCES, SIGLO CERO, infoprofesionales, la web de FEAPS, las notas de prensa, las campañas sobre derechos: "mi voto cuenta", por ejemplo, etc., junto con la labor de los responsables de comunicación de las federaciones y sus medios de comunicación, más los de las entidades, han ido creando una percepción social sobre las personas con discapacidad intelectual radicalmente distinta de la que se tenía al nacer FEAPS, hace 50 años.

Otro capítulo importante que no se puede despreciar es las alianzas de FEAPS con las instituciones de la investigación y del conocimiento. FEAPS ha tenido especial relación en estos años con el INICO de la Universidad de Salamanca, la Universidad Autónoma de Madrid, la UNED, la Universidad de Valladolid, la Universidad de Valencia, la Universidad Ramón Llull de Barcelona... destacando, además de variados 
proyectos de investigación y de evaluación, el Máster en Integración y Calidad de Vida del INICO, el Máster en Calidad de Vida Familiar de la Universidad Autónoma de Madrid o el Máster en Consultoría y Gestión de Procesos de Desarrollo Organizacional de la Escuela de Empresariales de la Universidad de Valladolid; todos ellos coorganizados y codirigidos con FEAPS.

Es necesario poner de relieve la colaboración de INICO con FEAPS. El INICO ha sido el principal intermediario entre la AAMR y FEAPS, pudiendo contar, para ser aplicados en la práctica, con todas las novedades en los cambios de paradigma relacionados con la discapacidad intelectual y con los avances que singular o conjuntamente con FEAPS el instituto ha desarrollado.

Bien, la historia de FEAPS es una historia cargada de actividad y una historia de colaboración entre cientos de organizaciones y entre miles y miles de personas entre las que las personas con discapacidad intelectual o del desarrollo y sus familias cada vez están adquiriendo más presencia y protagonismo. Los demás estamos a su servicio.

\section{Referencias bibliográficas}

AAMR (1992). Retraso Mental. Definición, clasificación y sistemas de apoyo, Madrid: Alianza Psicología.

Bank-Mik kelsen, N. (1975). El principio de normalización. Siglo Cero, 37, 16-21. FEAPS.

Bradley, V. J. (1994). Evolution of a new service paradigm. En V. J. Bradley, J. W. Ashbaugh y B. C. Blaney (Eds.), Creating individual supports for people with developmental disabilities: A mandate for change at many levels.

EtXeberRia, X. (2008). La condición de ciudadania de las personas con discapacidad intelectual. Universidad de Deusto.

FEAPS (2003). Código Ético. http://www.feaps.org/archivo/centro-documental/cat_view/ 184-.html.

FEAPS (2012). Manifiesto por la plena ciudadanía de las personas con discapacidad intelectual o del desarrollo. http://www.feaps.org/archivo/centro-documental/cat_view/86-derechos. html? start=30.

FEAPS (2000). Manuales de Buena Práctica. Orientaciones para la calidad. 8 volúmenes.

FEAPS (2007). Modelo de Política de Personas.

FEAPS. Modelo de Responsabilidad Social. http://feapsresponsabilidadsocial.org/?page_id=4.

LOPEZ IgLESIAS, J. (2014). FEAPS 50 ANIVERSARIO. 50 años con las personas con discapacidad intelectual. FEAPS.

Ministerio de Sanidad, Servicios Sociales e Igualdad (2013). II Plan Estratégico del Tercer Sector de Acción Social 2013-2016. Centro publicaciones MSSSI.

OMS (1980). La clasificación internacional de deficiencias, discapacidades y minusvalías.

ONU (2006). Convención de Derechos de las Personas con Discapacidad.

Verdugo, M. Á., Gómez, L. E., Barias, B., Santamaría, M., Navallas, S. y Hierro, I. (2014). Escala San Martín. Evaluación de la calidad de vida de personas con discapacidades significativas. Santander: FOSM.

Verdugo, M. Á., TAmarit, J. et al. (2013). Escala INICO-FEAPS. Evaluación integral de la Calidad de Vida de personas con discapacidad intelectual o del desarrollo. Publicaciones INICO. Universidad de Salamanca. 